\title{
Review Paper: Oral Rehabilitation Using the Lip ๑) Muscle Trainer: A Narrative Review
}

\author{
Ali Mohamed Ali Ismail ${ }^{*}$ (iD) \\ 1. Department of Physical Therapy for Cardiovascular, Respiratory Disorder and Geriatrics, Faculty of Physical Therapy, Cairo University, Giza, Egypt.

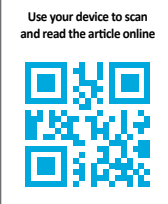 \\ ditation Ismail AMA. Oral Rehabilitation Using the Lip Muscle Trainer: A Narrative Review. Physical Treatments. 2021; \\ 11(3):139-144. http://dx.doi.org/10.32598/ptj.11.3.486.1 \\ dol http://dx.doi.org/10.32598/ptj.11.3.486.1
}

\section{(c) (1) (3)}

Article info:

Received: 04 Oct 2020

Accepted: 21 Feb 2021

Available Online: $01 \mathrm{Jul} 2021$

Keywords:

Lip muscle trainer, Patakara, Oral rehabilitation, Oral health

\begin{abstract}
A B S T RA C T
A lot of time is spent on exercising the body parts while the lips are neglected, despite the evidence on the wide-ranging effects of lips on overall health and quality of life. Oral rehabilitation by Patakara lip muscle trainer leads to a strong lip closure which can stand as the first-line defense mechanism against many oral dysfunctions related to aging. In the absence of a narrative review presented on this trainer, this paper focuses on the components, instructions for use, and oral health indications of the Patakara lip muscle trainer. This trainer could enhance many oral dysfunctions in the elderly as oral breathing, snoring, halitosis, dry mouth, and oral/ gastrointestinal dysfunction, but future studies are needed in this field.
\end{abstract}




\section{Highlights}

- Oral rehabilitation by Patakara lip muscle trainer can make a strong lip closure.

- Patakara can enhance many oral dysfunctions related to aging.

- Patakara can enhance oral breathing, snoring, and gastrointestinal dysfunction.

\section{Plain Language Summary}

Oral and perioral musculature exercising by Patakara lip muscle trainer must attract more attention from physicians, elderly patients, and physiotherapists. Strong oro-labial and tongue muscles are the main adjunctive rehabilitation method to treat many common elderly-occurred oral dysfunctions including oral breathing, snoring, halitosis (bad mouth), xerostomia (dry mouth), eating disorders, and dysphagia.

\section{Introduction}

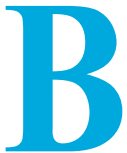

$\mathrm{y}$ incorporating different numbers and types of movements, lips are closed by the orbicularis oris muscle with additional muscles of the face that have muscle fibers going in different directions around the perioral area [1]. The functional, strong lip is vital as it can impact the different daily activities [2]. The orbicularis oris muscle is included in many functions like speech, mastication, and swallowing [3].

Sarcopenia is an aging process characterized by a continuous decrease in muscular mass, strength, and quality [4]. Different massive functional and structural changes occur with the aging process, including the tongue, oral and perioral tissues, oral sensation, and lips muscles [5]. Increased tooth loss associated with aging is a risk factor for weak tongue and lip muscles, especially in the elderly with less than 15 teeth [6]. The structure and consistency of the orbicularis oris muscle also show changes with aging, such as the shape of fibers, atrophy signs, smaller fascicles and bundles, and an increase in the surrounding layer of epimysium [7].

Strong lip closure is vital because the orbicularis oris strength declines with the aging process leading to incomplete lip closure and deteriorated oral environment due to the evaporation of saliva. Also, as a result of cerebrovascular injury, decreased lip closure strength reduces the movement of the tongue and affects all oral functions, including chewing, ingestion, and swallowing [3].

The interventions to perform facial muscle contractions by electrostimulation or oral rehabilitation devices increase the orofacial strength [8]. Functional exercise of the oral and facial muscles is called orofacial myofunctional therapy. Patakara lip muscle trainer - an oral rehabilitation device - is specially designed to boost uniform force application around the muscles of the lip, aiming for the enhancement of oral muscular strength [9].

Orofacial Myofunctional Training (OMT) is effective for improving tongue and lip closure strength. Oral strength should be maintained and enhanced, especially in the elderly, to improve their oral health and quality of life (QoL) [6]. Although the Patakara is not a new device, studies on using the Patakara lip muscle trainer are sparse. So this narrative review aims to address the importance of this device for oral health.

\section{Orofacial Myofunctional Training (OMT)}

OMT was introduced in orthodontic therapy primarily by Rogers in the early 1900 s. It aims to correct the atypical deglutition, myofunctional, and musculoskeletal problems in patients with growing dentition [10]. Also, it ensures nasal breathing, enhances oromuscular balance, and stimulates mandibular growth and normal swallowing [11].

Prefabricated oral myofunctional appliances were designed to be used with the help of orofacial and sometimes oropharyngeal muscle training [10]. OMT involves an individualized therapeutic program of resistive and passive orofacial muscle exercises. OMT re-educates the orofacial neuromuscular complex to normalize the facial muscle imbalances, retrain normal tongue posture, establish equilibrium between the tongue and the cheek muscles, and regain corrected chewing and swallowing patterns [12]. 
In 2000, the Japanese dentist, Dr Akihiro, created the Patakara lip muscle trainer (Patakara). It is a simple, non-invasive oral rehabilitation device that can improve the elderly's quality of life [13].

\section{Patakara components}

Patakara is a highly flexible, resilient plastic device [14] made from a highly elastic polymer plastic with rubber composite (polyester elastomer) [9]. It is placed in the oral vestibule between the upper and lower lips. Because of the high resilience of the device, it enables the direct conditioning of the oral muscles [14]. The device consists of mouthpiece Pataleara (main large body part of the device that enters the oral vestibule and has two parts, upper and lower sides) and plastic tabs (Figure 1).

\section{Instructions for using Patakara}

According to the instructions by Suzuki et al. [15], After closing the mouthpiece, Pataraka can be inserted into the oral vestibule between the upper and lower lips (between teeth and lips).

Without clenching teeth, the patient must touch the upper and lower sides of the device by the closed lips while the tongue contacts the incisive papilla between the closed lips for 5 minutes.

With the lips closed, stretching movements are performed by pulling the plastic tabs on the mouthpiece front 10 times each to all sides (front, lower and upper sides, and left and right sides).

During the stretching movements, continued firm lip closure should be kept to prevent the device release out of the mouth. The rehabilitation is performed at least for 5 minutes, 4 times daily, or more.

\section{Oral indications of Patakara}

According to the current research published, Patakara can address oral health problems such as breathing, snoring, halitosis, dry mouth, and oral/gastrointestinal dysfunction [13].

\section{Shift from mouth to nasal breathing}

Breathing is an essential function for life sustenance. Normal breathing is transmitted through the nose, pharynx, larynx, and trachea. Breathing through the nose and mouth or mouth only more than 6 months is defined as an abnormal mouth breathing pattern or habit. Mouth breathing is associated with incomplete closure of lip due to age-related weakness phenomena, dry mouth, tooth caries, periodontal diseases, oral malodor [16], weak orofacial musculature, the low resting position of the tongue [17], and dysfunction of airway dilator muscles in Obstructive Sleep Apnea (OSA) syndrome [18].

Among oral muscles, the orbicularis oris muscle is the main muscle included in labial closure. Labial closure strength (LCS) decreases from the middle of the fifth decade of age to reach its minimum value at over 80 years [19]. Weak tongue elevation and labial closure strength may cause snoring and mouth breathing during sleep. Having a strong lip seal (strong closure) and tongue by lip muscle trainer may facilitate nasal respiration and stop oral respiration. Lip muscle trainer decreases the symptom of apnea by strengthening the muscles of the lip, increasing lip closure force [15], and improved partial oxygen saturation [20].

\section{Snoring}

Snoring is highly prevalent in the elderly with some associated risk factors as wide neck circumference and obesity [21]. It is known that most snorers show a mouth breathing pattern during sleep. Snoring can be reduced theoretically by displacing the tongue anteriorly to compensate for the loss of the neuromuscular activity of the primary pharyngeal opening muscle known as genioglossus muscle [22]. Snoring can be improved by the lip muscle trainer due to the shift from mouth to normal nose breathing and by repetitive exercises that move the tongue into the anterior-superior oral cavity, which may enlarge the upper airway space [15].

\section{Halitosis}

By its psychological and social distresses, halitosis negatively impacts QoL in many patients suffering from this problem [23]. Because of its potent antimicrobial properties, saliva inhibits the growth of anaerobic and Gram-negative bacteria that enhance the production of malodorous substances and lousy mouth odor (Halitosis). Commonly, dry mouth is associated with mouth breathing, OSA, aging [20], and systemic diseases as diabetes mellitus [24]. A dry mouth increases the risk of halitosis because of reduced salivary flow. Using lip muscle trainer is associated with the elimination of halitosis, perhaps due to the increased salivary flow [20] in both its forms, stimulated and unstimulated, leading to a decreased number of the oral bacteria, improved oral mucosal tissue wetness in the elderly [25], increased upper airway space in OSA patients, and shift to normal breathing [15] 


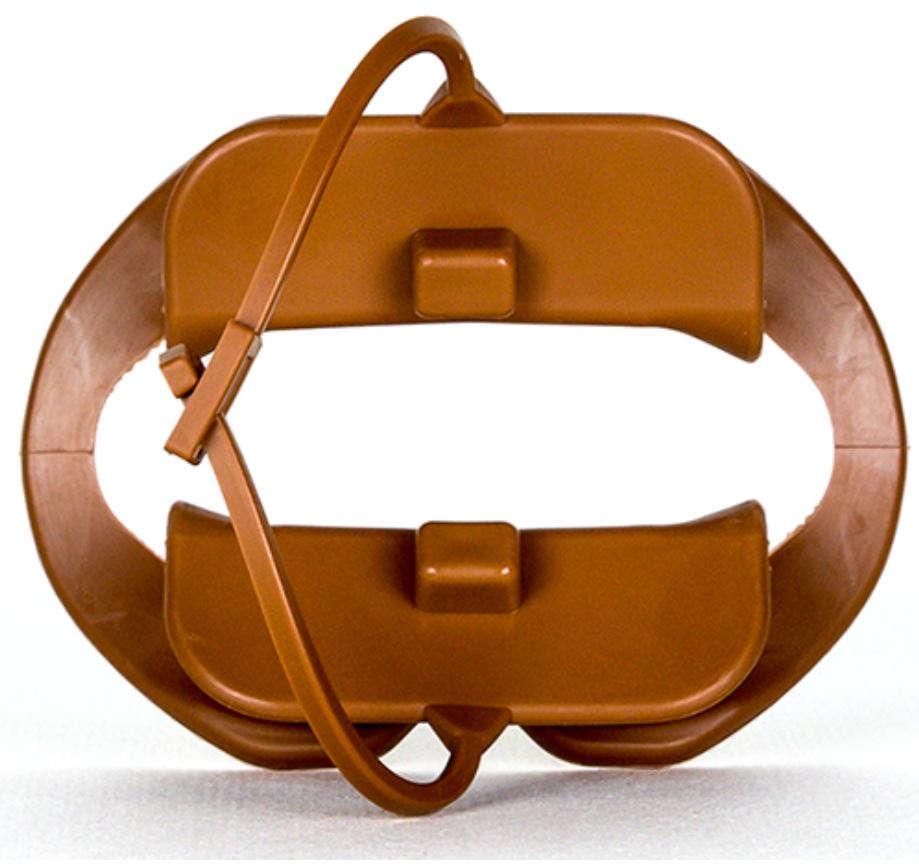

Figure 1. Patakara lip muscle trainer

PHYSICAL TREA $\ M E N T S$

\section{Dry mouth}

Dry mouth or xerostomia refers to the subjective symptom of reduced secretion of saliva, while hyposalivation is the objective finding of low saliva flow [24, 26]. These conditions not only increase the risks of periodontal disease and tooth decay but also leads to chronic inflammatory processes that can promote systemic and local oral infections, aspiration pneumonia, and threats to the main life-sustaining functions like feeding, swallowing, and upper gastrointestinal function [27].

Besides the increased oral wetness of the tongue and buccal mucosa, the Patakara improves unstimulated and stimulated saliva flow [14] and decreases the oral pain or discomfort related to chronic periodontitis [25].

Multiple systems may be involved in saliva stimulation. A reflex arch regulates salivation from the afferent arm (receptors and nerves), central connection and salivary nucleus, and an efferent arm. There is an aging-associated gradual loss of cells and functions of the motor nervous system. The afferent receptors and nerves in the facial muscles are triggered by repeated moved facial mimetic muscles with Patakara leading to salivary production increase. The facial muscles and some salivary glands are innervated by the facial nerve branches. Activation of facial muscles by the lip trainer activates the salivary flow rate by activation of both submandibular ganglion and salivatory nucleus. Stretched and trained facial muscles by Patakara may act as a rehabilitation tool to the deglutition organ, which activates salivation [14].

\section{Oral/Gastrointestinal functions}

The five swallowing phases are perceptive, pre-oral, oral, pharyngeal, and esophageal. These phases aim to transport the bolus of drink and food. Dysphagia is aggravated by common diseases like neurological diseases, cancer, and so on. Aging is associated with physiological hypofunctions in the normal pattern of swallowing due to decreased neuromuscular reserve with aging [28], loss of all teeth in some elderly, low masticatory efficiency, gradual loss of cross-sectional area and density of jaw muscles [29], decreased tongue muscle volume and pressure (which is the force required to move chewed food to the pharynx), downward shifted position of the larynx in some older people, the spread of the cavity of the pharynx, the delayed time and size of the opening of the upper esophagus sphincter [28].

Swallowing dysfunctions may be improved by repeated tongue strengthening exercises [30] incorporated during training by a lip muscle trainer [15]. Aging-associated decrease in the functional motor capacity of the tongue may be compensated by repeated isometric tongue exercises to increase the isometric tongue strength, accurate tongue pressure, control of bolus, and the functional dietary intake by mouth in the elderly [31].

Patakara device may enhance QoL of the elderly with eating disorders as the training of the facial mimetic muscles may improve the nasal respiration with better collaboration between nasal cavity, tongue position, larynx, and 
the airway. Many studies link the increased saliva secretion to the stimulated parasympathetic innervation after the use of the Patakara device. The same suggested link may support the improved gastrointestinal dysfunction and subjective gastrointestinal symptoms in the elderly as anorexia, early satiety, constipation, and epigastralgia, especially in ones with a poor nutritional state [19].

Higher-order brain functions deteriorate with aging [32]. Assessing human brain activity by topography from the scalp utilizing near-infrared light immediately after training showed high oxy- and deoxy-hemoglobin in the blood flow to the right frontal lobe [19]. Patakara stimulates local oral mechanical and somatosensory receptors that activate the trigeminal nerve through mesencephalic nucleus stimulation in the prefrontal cortex in the brain. Sensory feedback stimulation between these components is enhanced by repeated lip closure that guarantees the improving role of Patakara in lip and mastication strength in elderly with eating disorders [32].

Using food in the training of oral function increases the pulmonary aspiration risk. This risk can be easily avoided by the daily implementation of lip muscle trainer in the treatment of oral/eating dysfunction to further raising the importance of lip closure training in geriatrics [32].

\section{Conclusion}

Many normal physiological functions of the body may be declined by the aging process and aggravated by the presence of a disease or pathology. Normal oro-respiratory functioning is the main life-sustaining condition to maintain a good QoL and could be enhanced and or treated by oral rehabilitation devices such as Patakara lip muscle trainer. The usefulness of lip trainer not only is limited to increased local lip closure and tongue strength but also extend to many aspects of deteriorated oral functions.

Training of oral and perioral musculature by Patakara lip muscle trainer must draw more attention from physiotherapist researchers. Strong lip/tongue and orofacial muscles complex are considered the golden adjunctive rehabilitation way to treat oral dysfunctions such as oral breathing, snoring, halitosis, dry mouth, eating disorders, dysphagia, and gastrointestinal symptoms. There is an urgent need for future studies to investigate the effect of this hopeful rehabilitation tool on oral dysfunctions.

\section{Ethical Considerations}

\section{Compliance with ethical guidelines}

There were no ethical considerations to be considered in this research.

\section{Funding}

This research did not receive any grant from funding agencies in the public, commercial, or non-profit sectors.

\section{Conflict of interest}

The author declared no conflict of interest.

\section{References}

[1] Findık Y, Baykul T, Aydın MA, Esenlik E, Ordu BN. Evaluation of lip force in patients with unilateral and bilateral cleft lip. British Journal of Oral and Maxillofacial Surgery. 2017; 55(4):391-5. [DOI:10.1016/j.bjoms.2016.12.015] [PMID]

[2] Wong V, Abe T, Spitz RW, Bell ZW, Yamada Y, Chatakondi $\mathrm{RN}$, et al. Effects of age, sex, disease, and exercise training on lip muscle strength. Cosmetics. 2020; 7(1):18. [DOI:10.3390/ cosmetics7010018]

[3] Yanagisawa Y, Matsuo Y, Shuntoh H, Horiuchi N. Effect of expiratory resistive loading in expiratory muscle strength training on orbicularis oris muscle activity. Journal of Physical Therapy Science. 2014; 26(2):259-61. [DOI:10.1589/ jpts.26.259] [PMID] [PMCID]

[4] Fukada K, Kajiya K. Age-related structural alterations of skeletal muscles and associated capillaries. Angiogenesis. 2020; 23(2):79-82. [DOI:10.1007/s10456-020-09705-1] [PMID]

[5] Al-Drees AM. Oral and perioral physiological changes with ageing. Pakistan Oral \& Dental Journal. 2010; 30(1):26-30. https:// pesquisa.bvsalud.org/portal/resource/pt/emr-98516

[6] Kim SH, Kim MJ, Lee SH, Choi BW, Heo YJ. The effects of orofacial myofunctional training on the changes of lip and tongue strength in elderly people. Journal of Dental Hygiene Science. 2019; 19(4):279-87. [DOI:10.17135/ jdhs.2019.19.4.279]

[7] Penna V, Stark GB, Eisenhardt SU, Bannasch H, Iblher N. The aging lip: A comparative histological analysis of agerelated changes in the upper lip complex. Plastic and Reconstructive Surgery. 2009; 124(2):624-8. [DOI:10.1097/ PRS.0b013e3181addc06] [PMID]

[8] Abe T, Wong V, Spitz RW, Viana RB, Bell ZW, Yamada Y, et al. Influence of sex and resistance training status on orofacial muscle strength and morphology in healthy adults between the ages of 18 and 40: A cross-sectional study. American Journal of Human Biology. 2020; 32(6):e23401. [DOI:10.1002/ajhb.23401] 
[9] Ibrahim F, Arifin N, Rahim ZH. Effect of orofacial myofunctional exercise using an oral rehabilitation tool on labial closure strength, tongue elevation strength and skin elasticity. Journal of Physical Therapy Science. 2013; 25(1):11-4 [DOI:10.1589/jpts.25.11]

[10] Papageorgiou SN, Koletsi D, Eliades T. What evidence exists for myofunctional therapy with prefabricated appliances? A systematic review with meta-analyses of randomised trials. Journal of Orthodontics. 2019; 46(4):297-310 [DOI:10.1177/1465312519880558] [PMID]

[11] Boucher C, Charezinski M, Balon-Perin A, Janssens F, Vanmuylder N, Glineur R. Benefits of using a Trainer $\mathrm{T}_{4} \mathrm{~K}^{\circledast}$ myofunctional appliance after rapid palatal expansion: a prospective study on thirteen patients. Journal of Dentofacial Anomalies and Orthodontics. 2008; 11(1):30-44. [DOI:10.1051/odfen/20084210037]

[12] Idris G, Hajeer MY, Al-Jundi A. Soft-and hard-tissue changes following treatment of Class II division 1 malocclusion with Activator versus Trainer: A randomized controlled trial. European Journal of Orthodontics 2019; 41(1):21-8. [DOI:10.1093/ejo/cjy014] [PMID]

[13] Ismail AMA. A narrative review on the use of lip trainer (Patakara) in oral rehabilitation. Medical Research Journal. 2021; 6(2):153-6. www.journals.viamedica.pl/medical_research_journal 153

[14] Saleem M, Yoshinari N, Nakamura S, Sumi Y, Iwai Y, Ozaki $\mathrm{Y}$, et al. Improvement of salivary flow and oral wetness by a lip trainer device and sonic toothbrush in older Japanese men and women with dry mouth. Journal of Oral Science. 2019; 61(2):221-8. [DOI:10.2334/josnusd.18-0012] [PMID]

[15] Suzuki H, Yoshimiura M, Iwata Y, Oguchi S, Kawara M, Chow CM. Lip muscle training improves obstructive sleep apnea and objective sleep: A case report. Sleep Science. 2017; 10(3):128-31. [PMID] [PMCID]

[16] Kimura-Ueda K, Shimazaki K, Sugimoto K, Ono T. Influence of habitual mouth breathing on taste sensation. Orthodontic Waves. 2018; 77(1):24-30. [DOI:10.1016/j. odw.2017.12.003]

[17] Cassir N, Desplats E, Rompré P, Sorokin A. Efficacy and stability of orofacial myofunctional therapy on restoring mature pattern of swallowing and nasal breathing in children before orthodontic treatment [MSc. thesis]. Montreal: University of Montreal; 2016. http:/ / hdl.handle.net/1866/16429

[18] O'Connor Reina C, Plaza Mayor G, Ignacio-Garcia JM, Baptista Jardin P, Garcia-Iriarte MT, Casado-Morente JC. Floppy closing door epiglottis treated successfully with an mhealth application based on myofunctional therapy: A case report. Case Reports in Otolaryngology. 2019; 2019:4157898. [DOI:10.1155/2019/4157898] [PMID] [PMCID]

[19] Ishikawa M, Ishikawa S, Kamata H, Akihiro Y, Hamada U, Yonei Y. Efficacy of a health promotion program with facial mimetic muscle training in residents of a medical care facility for the elderly. Anti-Aging Medicine. 2010; 7(11):120-8. [DOI:10.3793/jaam.7.120]

[20] Yoshimiura M, Suzuki H, Tanaka H, Asakawa R, Chow CM, Kawara M. Lip muscle training improves halitosis and obstructive sleep apnea syndrome: A case report. Journal of Dental Sleep Medicine. 2016; 3(1):31-2. [DOI:10.15331/jdsm.5372]
[21] Adebusoye LA, Ogunbode AM, Olowookere OO. Factors associated with reported snoring among elderly patients attending the geriatric center in Nigeria. Pan African Medical Journal. 2014; 19:309. [DOI:10.11604/pamj.2014.19.309.5244] [PMID] [PMCID]

[22] Engelke W, Repetto G, Mendoza-Gaertner M, Knoesel M. Functional treatment of snoring using oral shields in conjunction with the tongue repositioning manoeuvre. International Journal of Odontostomatology. 2007; 1(2):133-9. http://www.ijodontostomatology.com/wp-content/uploads/2018/03/Functional_Treatment.pdf

[23] Lu HX, Chen XL, Wong MCM, Zhu C, Ye W. Oral health impact of halitosis in Chinese adults. International Journal of Dental Hygiene. 2017; 15(4):e85-92. [DOI:10.1111/idh.12242] [PMID]

[24] Ismail AMA, Mohammed Ezz El-din H, Elsayed Mohamed Abdel M. Impact of Transcutaneous Electrical Nerve Stimulation (TENS) on hyposalivation in type 2 diabetics. Bioscience Research. 2019; 16(1):690-4. https://www.isisn.org/ BR16(1)2019/690-694-16(1)2019BR18-599.pdf

[25] Akinori M, Keita K, Kiyohito K. [The Effect of the oral environmental improvement by the oral myofunctional therapy for elderly patients with chronic periodontitis (Japanese)] The Japanese Journal of Conservative Dentistry. 2014; 57(2):180-7. [DOI:10.11471/shikahozon.57.180]

[26] Ismail AMA. Hyperbaric oxygen therapy as a complementary or alternative therapy for chronic oral and gastrointestinal disorders: A narrative review. International Journal of Alternative and Complementary Medicine. 2020;1(2):33-40. https:/ / www. saap.org.in/journals/index.php/ijacm/article/view/114

[27] Kandelman D, Petersen PE, Ueda H. Oral health, general health, and quality of life in older people. Special Care in Dentistry. 2008; 28(6):224-36. [DOI:10.1111/j.17544505.2008.00045.x] [PMID]

[28] Chiba Y. Short-term effectiveness of a swallowing exercise for the elderly using day-care services. Journal of Nursing and Care. 2013; S5:2-7. [DOI:10.4172/2167-1168.S5-012]

[29] Weijenberg RA, Scherder EJ, Lobbezoo F. Mastication for the mind-the relationship between mastication and cognition in ageing and dementia. Neuroscience \& Biobehavioral Reviews. 2011; 35(3):483-97. [DOI:10.1016/j.neubiorev.2010.06.002] [PMID]

[30] Langmore SE, Pisegna JM. Efficacy of exercises to rehabilitate dysphagia: A critique of the literature. International Journal of Speech-Language Pathology. 2015; 17(3):222-9. [DOI:10.3109/17549507.2015.1024171] [PMID]

[31] Safi MF, Wright-Harp W, Lucker JR, Payne JC, Harris O. Effect of neuromuscular electrical stimulation on labial and lingual weakness. Topics in Geriatric Rehabilitation. 2018; 34(2):145-54. [DOI:10.1097/TGR.0000000000000185]

[32] Takamoto K, Saitoh T, Taguchi T, Nishimaru H, Urakawa S, Sakai S, et al. Lip closure training improves eating behaviors and prefrontal cortical hemodynamic activity and decreases daytime sleep in elderly persons. Journal of Bodywork and Movement Therapies. 2018; 22(3):810-6. [DOI:10.1016/j. jbmt.2017.09.002] [PMID] 